\title{
El rotativo El Día de las Islas Canarias durante la II Guerra Mundial (1939-1945)*
}

\section{Resumen}

En los párrafos siguientes, nos hemos propuesto comprobar en el subsistema informativo más periférico del estado español, las Islas Canarias, el discurso de la prensa franquista ante los avatares de la II Guerra Mundial. Para ello, hemos recurrido al periódico El Día, cuyas páginas hemos analizado con el propósito de detectar la evolución de su línea editorial dentro de la uniformidad impuesta por la victoriosa España nacional. La investigación ha dejado en evidencia que, tras perder su tradicional apertura al exterior al quedar subsumido en el aparato propagandístico de la dictadura, este archipiélago nos legó, a remolque de los temores ante el giro político del régimen, la escasez de ideólogos propios y la demora con la que llegaban las consignas de Madrid, una versión muy comedida y, por ello, nítida de la argumentación esgrimida por el régimen para alejarse de la Alemania nazi y acercarse a los Estados Unidos.

\section{Palabras clave}

Tesauro: Franquismo, propaganda, II Guerra Mundial, Islas Canarias, El Día $(1939 \ldots)$.

Referencia bibliográfica para citar este artículo: Yanes Mesa, Julio Antonio. "El rotativo El Día de las Islas Canarias durante la II Guerra Mundial (1939-1945)". Anuario de Historia Regional y de las Fronteras 26.1 (2021): 273-292.

Fecha de recepción: 16/05/2020

Fecha de aceptación: 7/09/2020

Julio Antonio Yanes Mesa: Doctor en Historia de la Universidad de la Laguna. Profesor titular en Historia y Periodismo, de la universidad antes mencionada. Código ORCID: 0000- 0003-2061-9268. Correo electrónico: jayanes@ull.edu.es.

\footnotetext{
* El artículo es resultado de un ejercicio investigativo independiente.
} 


\title{
The Newspaper El Día of the Canary Islands During the World War II, (1939-1945)
}

\begin{abstract}
With this article, we have proposed to verify the information subsystem most unique of the Spanish state, the Canary Islands, the positioning of the Francoist press before World War II. To this end, we analyzed the editorial line of the newspaper El Día, to detect specific features of the evolution of speech. Finally, research has revealed that, regardless of being subsumed in the central propaganda apparatus of the dictatorship, El Día gave us an argument supporting the turn of the Franco regime in those tragic years too restrained for fear of antagonizing the watchwords for the distance, which, fleeing from the excesses dialectical other newspapers, reflects the process that made Franco away from Nazi Germany to the service of the United States.
\end{abstract}

Keywords

Tesauro: Franco, Propaganda, World War II, Canary Islands, El Día (1939...).

\section{O jornal El Día das Ilhas Canárias durante a Segunda Guerra Mundial (1939-1945)}

\section{Resumo}

Nos parágrafos que seguem, propusemos verificar no subsistema informativo mais periférico do estado espanhol, as ilhas Canárias, o discurso da imprensa franquista antes das vicissitudes da Segunda Guerra Mundial. Para isso, recorremos ao jornal El Día, cujas páginas foram analisadas para detectar a evolução de sua linha editorial dentro da uniformidade imposta pela vitoriosa Espanha nacional. A investigação mostrou que, depois de perder sua tradicional abertura para o mundo exterior por ser subsumido no aparelho de propaganda da ditadura, este arquipélago nos legou, a reboque dos temores da virada politica do regime, a escassez de seus próprios ideólogos e a demora com que chegaram os slogans de Madrid, uma versão muito contida e, portanto, clara da argumentação usada pelo regime para se afastar da Alemanha nazista e se aproximar de os Estados Unidos.

\section{Palabras-chave}

Tesauro: Franquismo, propaganda, Segunda Guerra Mundial, Ilhas Canárias, El Día $(1939 \ldots)$. 


\section{Introducción}

Como es conocido de sobra, desde finales de la Guerra Civil hasta la entrada en vigor de la llamada Ley Fraga de 1966, la prensa española estuvo regulada por la ley de 22 de abril de 1938, cuyo promotor fue Ramón Serrano Súñer, cuñado y, por entonces, hombre de confianza del general Franco. En síntesis, la legislación puso a todos los periódicos, incluidos los privados, "al servicio del Estado", ${ }^{1}$ lo que equivale a decir al servicio del régimen franquista, mediante un mecanismo de control muy minucioso que contemplaba la colocación de personas de confianza al frente de cada órgano informante en calidad de director-censor, la indicación de los criterios que debían guiar la elaboración de las informaciones y opiniones del día a día a través de consignas $^{2} \mathrm{y}$, por si fueran pocas las cautelas, la censura previa. Todo ello, unido a la autocensura de los periodistas para alejar todo atisbo de sospecha de antipatías por el estado de cosas reinante, hace comprensible que la unanimidad haya sido el rasgo más característico de la prensa española en los años de la II Guerra Mundial, hasta el extremo de hacer hablar a muchos autores de la ausencia de matices diferenciales entre las cabeceras falangistas, monárquicas y católicas, ${ }^{3}$ las tres corrientes ideológicas subyacentes al franquismo. Sin embargo, un factor geográfico que hasta el momento no ha sido tenido en cuenta, la lejanía de las Islas Canarias muy bien pudo introducir algún rasgo singular dentro de la uniformidad imperante en aquellos trágicos, cuestión que nadie se ha encargado todavía de comprobar.

En los renglones que siguen, nos proponemos estudiar la postura de la prensa franquista durante la II Guerra Mundial en el enclave más periférico de España, las Islas Canarias, un archipiélago que por su situación geográfica atrajo la atención de los dos bandos contendientes sin que ninguno de ellos llevara luego a cabo, por diversas circunstancias, sus planes de ocupación. ${ }^{4}$ En concreto, vamos a analizar las secciones de opinión del único diario matutino editado por entonces en la zona occidental del archipiélago, El Día, al objeto de calibrar, sin apriorismo alguno que encauce la interpretación de los textos, la reacción del periódico ante el cambiante curso de los acontecimientos para, con ello, entresacar los rasgos distintivos, si es que los hubo, de su discurso dentro del común de toda la prensa española. A tal fin, consultamos todos y cada uno de los números editados por el citado rotativo durante la II Guerra Mundial en las hemerotecas de la Universidad de La Laguna, sobre sus ediciones en papel, y en la del TEA de Santa Cruz de Tenerife, donde se conservan microfilmados. ${ }^{5}$

\footnotetext{
${ }^{1}$ Manuel Fernández Areal, El control de la Prensa en España (Madrid, Guadiana, 1973) 177-193.

2 Justino Sinova, La censura de Prensa durante el franquismo (1936-1951), (Madrid, Espasa-Calpe, 1989) 161-275.

${ }^{3}$ Al margen de los clásicos citados en las dos notas anteriores, véase: Ramón Tena Fernández, Ana Margarida Ramos y José Soto Vázquez, "Análisis comparativo de la censura de la LIJ en España y Portugal a través de la legislación promulgada durante las dictaduras de Franco y Salazar", Bulletin of Spanish Studies, 96, 10 (2019): 1657-1679; y Encarnación Lemus y Manuel Peña (coord.), Alianzas y propaganda durante el primer franquismo (Barcelona, Ariel, 2019).

${ }^{4}$ Juan José Díaz Benítez, Canarias indefensa: los proyectos de ocupación de las islas durante la II Guerra Mundial, (Santa Cruz de Tenerife, Ediciones Idea, 2008) 70-343.
}

${ }_{5}^{5}$ Aunque no pudimos trabajar con las galeradas previas con las correcciones de la censura, sencillamente, 
La metodología giró en torno al análisis de contenido y la incardinación de cada texto en su contexto a la luz del estado de la cuestión, lo que en el caso de las Islas Canarias se reduce, sin abordar la cuestión que nos ocupa, a las citadas aportaciones de Víctor Morales Lezcano y Juan José Díaz Benítez. Recientemente, aunque ha salido a la luz un trabajo de Marta García Cabrera sobre la prensa canaria en la II Guerra Mundial, este está circunscrito al diario Falange de Las Palmas, reducido al año y medio corto comprendido entre agosto de 1939 y finales de 1940 y centrado, específicamente, en el paso del régimen de la neutralidad a la no beligerancia. ${ }^{6}$

\section{La singularidad del contexto estudiado}

Las Islas Canarias, con su emplazamiento en el océano Atlántico, a más de un millar y medio de kilómetros de Europa y a un centenar escaso de África, constituyen el espacio geográfico, cultural y económico más singular del actual territorio del estado español. Los problemas derivados de la lejanía y la escasez de recursos propios, han sido solventados con una singularidad climática que, históricamente, ha permitido a la economía isleña girar en torno a las demandas coyunturales de Inglaterra y, en general, de los países más desarrollados de Europa Occidental, en tanto en cuanto éstas no han podido ser satisfechas por otras vías. En los años estudiados por nosotros, tal estrategia estaba centrada en la producción de plátanos, tomates y papas tempranas, lo que, a su vez, había conllevado el desarrollo portuario, de un lado, con el envío de las partidas al viejo continente y, de otro, con la prestación de los servicios de aguada y carboneo a los buques de paso. Aunque para paliar las secuelas de la Gran Depresión de 1929 Madrid había abierto progresivamente el mercado peninsular a la producción frutera isleña, cuando estalló la II Guerra Mundial, buena parte de ésta aún recalaba en Francia e Inglaterra, esto es, en los países enfrentados con la Alemania nazi que, a la postre, era la referencia ideológica del franquismo. En consonancia con su fuerte dependencia del exterior, pues, las islas quedaron a partir de entonces inmersas en una profunda crisis porque, a pesar de haber quedado al margen de los efectos de las operaciones bélicas de la Guerra Civil, su economía había quedado estrangulada por la pérdida de los mercados exteriores. ${ }^{7}$

A nivel informativo, la singularidad canaria en el seno del estado español no era menos acusada, tal y como podemos comprobar con un somero vistazo al sector en los años previos al período estudiado. Así, antes del estallido de la Guerra Civil, cuando la radiodifusión española ya había adquirido un cierto desarrollo, la prensa isleña todavía disfrutaba su edad de oro porque la radio autóctona aún estaba en estado embrionario y las señales de las emisoras foráneas eran muy difíciles de sintonizar. Bajo tales premisas, y teniendo en cuenta que los enlaces marítimos

porque estas no se conservan, la actitud cautelosa del periódico por las razones comentadas nos deja entrever que pocos, por no decir ninguno, problemas debió tener con la censura.

${ }^{6}$ Marta García Cabrera, "De la neutralidad oficial a la no beligerancia española en la II Guerra Mundial: análisis a través de la prensa canaria”, Anuario de Estudios Atlánticos, 64 (2018): 1-18. URL: anuariosatlanticos.casadecolon.com/index.php/aea/article/view/10162/9644.

${ }^{7}$ Juan José Díaz Benítez, Anglofilia y autarquía en Canarias durante la Segunda Guerra Mundial (Santa Cruz de Tenerife, Ediciones Idea, 2008) 97-267. 
retardaban la llegada de los competitivos rotativos madrileños en varios días, cosa que no sucedía en la periferia de la península porque aquí llegaban a diario por tren, el matutino La Prensa (1910-1939) y el vespertino La Tarde (1927-1982) seguían saboreando, acaso, en el último escenario occidental, aquella irrepetible coyuntura en la que el periodismo escrito, una vez emancipado del tutelaje político al calor del desarrollo empresarial, monopolizó el servicio de la noticia al no acusar aún la competencia de las ondas hertzianas. ${ }^{8}$ No menos singular dentro del centralizado sistema informativo franquista durante la Guerra Civil fue el papel del subsistema isleño, cuando el bando sublevado contra la República aprovechó el emplazamiento atlántico del archipiélago para montar, tras el inmediato control de este, la mayor plataforma radiofónica de propaganda exterior de la España nacional. ${ }^{9}$ Precisamente ha sido este hecho diferencial lo que nos ha aconsejado comprobar si la uniformidad impuesta en la prensa por el régimen franquista conoció en las Islas Canarias, al calor del desgajamiento de la península, algún rasgo específico en la II Guerra Mundial. ${ }^{10}$

\section{Las características básicas del medio de comunicación analizado}

El Día apareció en Santa Cruz de Tenerife el 15 de febrero de 1939, a un mes y medio escaso de la finalización de la Guerra Civil, como fruto de la fusión del prestigioso rotativo de sustrato republicano La Prensa (1910-1939), confiscado por los militares rebeldes tras la sublevación contra la República, con el órgano de Falange Española Tradicionalista y de las JONS, Amanecer, este promovido el 1 de agosto de 1937 sin que, hasta entonces, diera la más mínima señal de poder rebasar el círculo de los correligionarios para calar en la sociedad insular. ${ }^{11}$ Gozando del privilegio de monopolizar el mercado lector de la mañana porque los restantes diarios matutinos de la provincia fueron clausurados por el régimen, El Día reflejaba las estrecheces de la época con un semblante austero y una oferta informativa oscilante entre las 4 y las 8 páginas que, con frecuencia, reducía a 2 por la escasez de papel y, muy excepcionalmente, incrementaba hasta 16 para conmemorar las efemérides y los hechos más celebrados por los golpistas. La tirada, inferior a los diez mil ejemplares, circulaba casi exclusivamente entre los 300.000 habitantes de la zona occidental del archipiélago, donde era el órgano oficial del Movimiento nacional-sindicalista, dado que la oriental estaba cubierta por Falange de Las Palmas, otro diario del mismo cuño nacido el 9 de diciembre de 1936 que, por las mismas fechas, también fue favorecido con el cierre de toda la competencia.

\footnotetext{
${ }^{8}$ Julio Antonio Yanes Mesa, "The Final Setting of the Golden Age of the Press in the World: The Canary Islands During the Spanish Second Republic (1931-1936)", Ámbitos. Revista internacional de comunicación, 19 (2010): 284-296.

${ }^{9}$ Julio Antonio Yanes Mesa, "La propaganda radiofònica de 1'Espanya nacional a Canàries Durant la Guerra Civil, 1936-1939”, Anàlisi. Quaderns de comunicació y cultura, 41 (2011): 101-116.

${ }^{10}$ Como el grueso de los artículos analizados aparecieron en la primera página, hemos optado por indicar la localización de todos ellos en el cuerpo del texto del artículo, lo que, a su vez, no ha permitido reducir el número de las notas a pie de página.

${ }^{11}$ Julio Antonio Yanes Mesa, Leoncio Rodríguez y «La Prensa»: una página del periodismo canario, (Santa Cruz de Tenerife, Cabildo Insular de Tenerife, 1995) 95-154.
} 
En los años de la II Guerra Mundial, la opinión y la propaganda tenían una presencia tan destacada en el naciente diario tinerfeño que, en paralelo a los editoriales, se abrieron unas pequeñas columnas sin firma en primera página bajo epígrafes tales como "El Día", "Guion” o "Pregón”, así como recuadros en cualquier parte del paginado con tipos de letra destacados en los que se difundían mensajes muy cortos a modo de consignas y eslóganes. El contenido de todas estas secciones se cubría con los textos que llegaban de Madrid a través de la estación radiofónica de onda corta $E A-8-A S$ de la Comandancia Militar de Canarias o, con días de demora, de los rotativos madrileños Arriba, El Español, El Alcázar o $A B C$, toda vez que los escritos de producción propia, tanto de los redactores como de los ideólogos isleños, fueron ocasionales y publicados sin firmas por la redacción del periódico. A remedo del rotativo matutino, desarrollaba su labor el otro diario de la provincia que consiguió mantener la edición, La Tarde, tanto por su carácter vespertino como por la militancia de su director con los insurrectos contra la República. En definitiva, El Día fue en estos años un producto informativo hermético por el temor de los militares y los civiles encargados de su edición a no seguir fielmente la tornadiza orientación ideológica que marcaba el naciente régimen desde Madrid. La ausencia de responsables a título individual de los textos de elaboración propia se debió más a esta circunstancia foránea que al temor a los censores provinciales, dada la fuerte vinculación de unos y otros en el microcosmos insular, ${ }^{12}$ por lo que el visado de los sucesivos números en el gobierno civil de la provincia antes de su distribución fue en estos años un simple trámite. ${ }^{13}$

\section{La inequívoca orientación nazi antes del estallido de la II Guerra Mundial}

En los cinco meses que median entre la finalización de la Guerra Civil y el inicio de la invasión, el 1 de septiembre de 1939, de Polonia por la Wehrmacht, El Día movió su línea editorial dentro de la más pura ortodoxia fascista. Este inequívoco alineamiento quedó reflejado en editoriales como el que, el 20 de abril, con motivo del 50 aniversario del nacimiento de Hitler, afirmaba que "España y Alemania tienen un común destino ecuménico [...] Esta es la trilogía de la Europa de nuestros días: Italia, Alemania y España." Tales tesis conllevaban el apoyo incondicional a la política anexionista del Führer, lo que 29 de abril, el día siguiente al del discurso pronunciado por este en el parlamento alemán exigiendo a Polonia la restitución del enclave de Dantzig, ${ }^{14}$ llevó al periódico a hablar de "las aspiraciones justas y eternas de un pueblo fuerte que solo quiere lo suyo.” Por debajo de tal actitud latía el convencimiento de que las amenazas de los países aliados no iban a pasar de las palabras a los hechos, tal

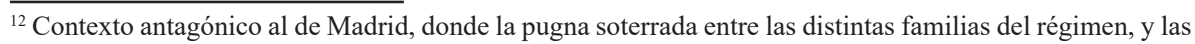
rencillas personales, se tradujeron en mutilaciones de los paginados, multas y suspensiones.

${ }^{13}$ Algo muy distinto sucedería en el tardofranquismo, cuando, una vez devuelto en 1955 a los herederos de Leoncio Rodríguez y bajo la dirección de Ernesto Salcedo Vílchez, El Día recibió varias sanciones gubernativas por su postura aperturista y crítica con la dictadura (Francisco Estupiñán Bethencourt, La escritura entre líneas. El artículo de opinión en El Día entre 1966 y 1975, Santa Cruz de Tenerife: Universidad de La Laguna, 1998).

${ }^{14}$ Este fue el último de los discursos de Hitler que Radio Club Tenerife retransmitió en directo, a través de la onda corta de la radiodifusión alemana, para las Islas Canarias, al calor de la autonomía que conservaba la emisora isleña desde el estallido de la Guerra Civil (Yanes Mesa, "La propaganda radiofònica") 101-116.
} 
y como se puede comprobar en el recuadro publicado en negritas el 2 de julio, en la cuarta página, a modo de editorial: "lo que tenía que suceder en Checoslovaquia [se refiere a las anexiones territoriales previas] sucedió. Lo que tenga que producirse en Dantzig, se producirá... [y]... la actitud pérfida de las democracias contra los países totalitarios no irá más allá del cerco económico, de la lucha sorda."

Paralelamente, la argumentación pro nazi estaba aderezada con un sinfín de peroratas dirigidas contra los mandatarios de las democracias parlamentarias y, sobre todo, contra Roosevelt, a quien censuraba su intromisión en las cuestiones europeas por sus llamamientos al diálogo para resolver los problemas territoriales existentes. Sin duda alguna, el texto más revelador que al respecto publicó el periódico data del 16 de abril cuando, aplicando la célebre doctrina de Monroe, "América para los americanos" (en realidad, "para los estadounidenses"), reivindicaba "Europa para los europeos" (en este caso, "para el fascismo") añadiendo: "Norteamérica, ¿qué busca en Europa? [...] Comerciantes, prestamistas, contabilidad y cálculo, he aquí su signo específico [...] Frente a este sistema de dominio que se funda en el poder económico, Europa es el foco del arte, de la filosofía y de todas esas manifestaciones del pensamiento." No menos elocuente fue el editorial que el 23 de abril censuraba la postura de Roosevelt ante las tensiones generadas por la política anexionista de Hitler en estos términos: "lleno de una ideología democrática, hablaba de que América está dispuesta al mantenimiento de la paz, al desarme y a un mejor reajuste económico del mundo. Claro que partiendo de un mundo ideológico como el de Roosevelt es difícil que se abra camino una comprensión sincera de la situación de Alemania."

Para completar las referencias sobre las que pivotaba la línea editorial del rotativo tinerfeño, nos resta añadir la animadversión contra el comunismo heredada de la Guerra Civil que, en estos meses prebélicos de tanta identificación con la Alemania nazi, oscureció hasta el extremo de llegarla a supeditar a los intereses de Hitler. Tal es lo que ocurrió, por ejemplo, tras la firma del pacto de no agresión germano-soviético que facilitaba la anexión alemana de Dantzig, lo que el 23 de agosto, a una semana vista de la invasión de Polonia, catalogó de "golpe maestro" de la diplomacia germana.

\section{La actitud expectante en los meses iniciales de la contienda}

Tras la declaración de la guerra por Inglaterra y Francia a Alemania, ${ }^{15}$ el órgano oficial del Movimiento en Tenerife, en coherencia con la neutralidad adoptada por el régimen franquista, quedó a la expectativa del desarrollo de las primeras operaciones bélicas conservando su identificación con la causa del Führer. Bajo tales premisas, el rasgo del discurso que más se diferenció de la etapa anterior fue el mayor peso que, a partir del ataque de la Unión Soviética a Finlandia, adquirieron las viejas embestidas contra el comunismo, al que, insistía una y otra vez, Franco había derrotado

\footnotetext{
${ }^{15}$ Las vicisitudes de la guerra se pueden seguir, entre otros autores, en: Stanley G. Payne, El régimen de Franco, 1936-1975 (Madrid, Alianza Editorial, 1987); del mismo autor, Franco y Hitler. España, Alemania, la Segunda Guerra Mundial y el Holocausto (Madrid, La Esfera, 2008); y Javier Tusell, Franco, España y la II Guerra Mundial. Entre el Eje y la neutralidad, (Madrid, Temas de Hoy, 1995).
} 
en la recién finalizada Guerra Civil. A tanto llegaron las fobias marxistas en aquellos meses, que el periódico enfrió su radical germanofilia para, el 10 de diciembre de 1939, felicitar a uno de los enemigos de Hitler, el presidente francés Daladier, por condenar el ataque ruso a Finlandia y liquidar, una vez disuelto e ilegalizado, los bienes del Partido Comunista de Francia. Otro tanto sucedió el 20 de enero de 1940 cuando, en otro editorial, se colocó por encima de los dos bloques enfrentados para afirmar que "el bolchevismo no es una doctrina social, sino el instinto atávico de las hordas asiáticas empujadas por un oleaje de invasiones." Pero luego, tras la firma del armisticio por Finlandia, el diario tinerfeño concentró sus arremetidas contra las democracias parlamentarias porque, según dijo el 15 de marzo de 1940, "con su cobardía y su indecisión... [habían facilitado]... el triunfo al tirano rojo," olvidando que Hitler había propiciado tales hechos con la firma del pacto germano-soviético.

En este tramo inicial de la guerra en el que el desenlace era imprevisible, El Día justificó la neutralidad del régimen franquista con argumentos de todo tipo que, muchas veces, contradecían las tesis defendidas en los meses de anteguerra. Así, mientras el 7 de abril de 1940 hacía suyo en la cuarta página un editorial del diario madrileño Arriba para afirmar que "la paz es una cosa de los neutrales que nadie tiene el derecho de turbar de ningún modo," un año atrás, el 15 de abril de 1939, había desatado una dura campaña contra "los neutros" dentro de España en su afán de crear un estado totalitario, a los que tildó de "gentecillas epicenas que nadie sabe de dónde vienen ni a donde van [...] que no son carne ni pescado y, como el agua tibia, dan náuseas." En consecuencia, el desconcertante diario movía la línea editorial con una argumentación tan poco consistente que, según argüía con reiteración, lo que era inaceptable para los ciudadanos españoles en el franquismo era un derecho para la España franquista en las relaciones internacionales. Luego, al compás que habrían de marcar los acontecimientos, el periódico haría de la incoherencia su norma de conducta para adaptarse a los imperativos del momento y, con ello, bregar a favor de la perpetuación del franquismo.

Tras la espectacular invasión alemana de los Países Bajos, el diario tinerfeño seguía insistiendo en la neutralidad del régimen franquista sin poder disimular, de manera cada vez más evidente, su creciente admiración por el poderío de la Wehrmacht. Así, mientras el 18 de mayo de 1940 decía que "la juventud alemana está cumpliendo en esta hora con su destino histórico," tres días más tarde, el 21 de mayo, añadía que "España fue a la guerra cuando solo con ella podía salvarse y salvar la frágil, reciente y nueva civilización en Europa. Consiguió su fin y ahora sirve a la paz por iguales motivos." Pero pronto, al percatarse de que el avance alemán tampoco era frenado por Francia, El Día cambio súbitamente el hilo argumental de su línea editorial.

\section{El alineamiento con la Blitzkrieg (la guerra relámpago) de la Alemania nazi}

En efecto, tras la capitulación, el 28 de mayo de 1940, de Bélgica, el discurso del diario tinerfeño adquirió un tono intervencionista que mantuvo en meses sucesivos hasta finales de año, cuando la obstinada resistencia inglesa y los crecientes rumores 
sobre la incorporación de los Estados Unidos dejaron entrever que la guerra, hasta el momento decantada claramente del lado alemán, iba para largo. Así, en esos siete meses en los que Franco, encandilado por el incontenible avance alemán en Europa, había reemplazado desde el 12 de junio la neutralidad por la no beligerancia ${ }^{16}$ para exteriorizar, ahora sin ambages, de que España, aunque no intervenía en las operaciones bélicas, estaba alineada con las potencias fascistas, el órgano oficial del Movimiento tinerfeño engarzó la Guerra Civil española con la que ahora sostenían sus países afines, reivindicó la españolidad de Gibraltar, habló de los asuntos territoriales pendientes de España e, incluso, llegó a hacer algún que otro amago de intervención en el conflicto.

Como sucediera con todas las cuestiones delicadas, la primera vez que $E l$ Día se atrevió a abordar el problema de Gibraltar lo hizo con el respaldo de algún editorial o artículo de autoría publicado previamente por la prensa madrileña que, evidentemente, ya tenía el visto bueno de la censura. Tal es lo que ocurrió el 1 de junio de 1940, cuando el periódico se hizo eco de un texto de Manuel Aznar inserto en el diario Arriba; o el 6 de junio, en el momento en que las tropas alemanas rompían con pasmosa facilidad la línea Weygand e iniciaban la invasión de Francia, cuando El Día recreó los comentarios del diario El Alcázar sobre la célebre sentencia, "Gibraltar: la gran vergüenza española," del desaparecido abogado y político carlista Juan Vázquez de Mella (1861-1928). Semanas más tarde, el 27 de julio, una vez que Inglaterra se había convertido en el único país sobreviviente a la embestida alemana, el rotativo tinerfeño ya se atrevía a afirmar, aunque sin explicitar el motivo, que "si ahora las actitudes de provocación de la Gran Bretaña nos movieran de nuevo a luchar por la dignidad y libertad de España, venceríamos nuevamente." Pero como es de sobra conocido, tales amenazas quedaron en una simple bravuconada porque meses más tarde, después de la entrevista con Hitler en Hendaya de octubre de 1940, Franco siguió sin inmiscuir a España en la contienda.

Tras la declaración de la guerra a Francia e Inglaterra por Mussolini el 12 de junio de 1940, el mismo día que Franco decidió reemplazar el estatus de neutralidad por el de no beligerancia, El Día exteriorizó con sus elogios a Italia los fuertes lazos ideológicos que, en aquella coyuntura triunfante para las tropas alemanas, lo acercaban tanto a los países fascistas como lo alejaban de los aliados: "frente a las democracias cargadas de charlatanería, obtusas y culpables de tantas tragedias, se pone en línea de combate este pueblo latino juvenil y heroico [...] también en el mundo hay una España joven, resurgida, mediterránea y cesárea. Que frente a nosotros hay una promesa de imperio". Dos días más tarde, en coincidencia con la ocupación de París, el rotativo tinerfeño apuraba un poco más su nueva postura para añadir que "nosotros, sinceramente, esperamos la victoria de las potencias del Eje con la misma ansiedad que esperábamos la victoria propia;" y al día siguiente, que "las democracias han sido en todos los tiempos, y lo son ahora, las enemigas enconadas de España." La creciente identificación con la causa fascista culminó el 20 de junio, cuando la rendición de

${ }^{16}$ Víctor Morales Lezcano, Canarias en la II Guerra Mundial, (Las Palmas de Gran Canaria, Edirca,1995) $27-52$. 
Francia era inminente, con la reivindicación de una parte de los éxitos de las tropas alemanas: "la batalla que ahora parece ya decidida se inició en la tierra de España en julio de 1936 y fue victoriosamente conducida y ganada por el Caudillo".

En estos siete meses en los que el arrollador avance alemán asombró a todo el mundo, la admiración del diario oficial del Movimiento en Tenerife por la Wehrmacht le hizo hablar el 21 de julio de 1940 de "la organización guerrera más formidable que han visto los siglos." Dos meses más tarde, con motivo de la visita del Ministro de Asuntos Exteriores español, Serrano Súñer, a Berlín, el belicoso diario resaltaba el 27 de septiembre que España no tenía nada que envidiar en el terreno militar a Alemania porque era "el pueblo más tradicionalmente guerrero del continente, curtido y forjado en campamentos de batallas." Insistiendo en la comunión existente entre los regímenes franquista y nazi, dos días más tarde volvía a enlazar la Guerra Civil con la mundial: "nuestra guerra no fue un mero incidente interior [...] Nuestra guerra fue, ni más ni menos, la elección de una postura resuelta y digna [...] al lado de los países que traían un nuevo pensamiento, un nuevo orden y un nuevo ideal sobre la Europa de alma cansada y entristecida." Por entonces, el 1 de octubre, esto es, tres semanas antes de la entrevista de Hendaya, El Día sacaba a relucir las presiones del sector partidario de intervenir en la guerra que encabezaba Serrano Súñer y las dudas que al respecto tenía Franco: "España tiene problemas internacionales que resolver [...] el Caudillo espera, tranquilo y sereno, por sentirse conducido, la hora de las grandes decisiones que, como siempre, Franco marcará, no cuando los impacientes lo deseen, sino cuando él lo crea justo y oportuno."

\section{Del apaciguamiento a la reducción de los enemigos a la Unión Soviética}

Desde inicios de 1941, al comprobar que la resistencia británica no cedía y que los rumores sobre la incorporación de los Estados Unidos a la guerra eran cada vez más insistentes, El Día abandonó sus veleidades intervencionistas sin alterar, de momento, su alineamiento con la todavía triunfante Alemania nazi. Aunque su repliegue derivaba del temor a una prolongación de la contienda, el 15 de abril de 1941, tras la fulminante campaña de los Balcanes con la que Hitler dio por controlado el viejo continente, afirmó que "la intervención de los Estados Unidos tan solo acrecentaría el valor alemán, que pondría en acción todos sus enormes medios de lucha." Por entonces, la identificación con la causa de las potencias del Eje seguía siendo tan acusada que al día siguiente, el 16 de abril, ante la reciente firma del pacto de no agresión ruso-japonés en Moscú, el periódico volvió a dejar en un segundo plano sus fobias contra el comunismo para decir que el citado acuerdo "ha sido un duro golpe asestado a las esperanzas anglosajonas de enturbiar las relaciones de Rusia con las potencias del Eje [...] con las consiguientes derivaciones a favor de Hitler, que espera terminar este mismo año la guerra." Semanas más tarde, el 3 de junio de 1941, ya en vísperas del ataque alemán a Rusia, el todavía incondicional diario germanófilo se atrevía a advertir a Roosevelt que "donde los ejércitos del Eje ponen sus plantas, bajen del aire o marchen a través de tierra firme, no hay obstáculo que no sea vencido y no hay poder que no sea aplastado". 
Paradójicamente, el alejamiento de la Alemania nazi y la paralela aproximación a los países aliados empezó a fraguarse el 22 de junio de 1941, cuando Hitler, sin previa declaración de guerra, decidió atacar a uno de los demonios del franquismo: la Unión Soviética. En efecto, aunque a los tres días de comenzar la campaña, el 25 de junio, El Día celebraba que "todos los pueblos de España vibran de júbilo en este instante por la decisión de Alemania de atacar a la fiera comunista en su propio cubil," la definitiva frustración de una guerra corta por el imprevisible rumbo que tomaban los acontecimientos le hizo volver, poco a poco, sobre sus pasos hasta recuperar, desde inicios de 1943, la neutralidad para, a renglón seguido, acelerar el acercamiento a los países aliados. En consecuencia, al abandono de las tesis intervencionistas sin renunciar, todavía, a la decantación por las potencias del Eje, se unió la progresiva concentración de sus iras, hasta entonces extendidas a todos los países aliados beligerantes, en Rusia. Luego, cuando el signo de la guerra cambió, el periódico solo tuvo que apelar a su radical anticomunismo para, de un lado, justificar su previo alineamiento con la Alemania nazi y, de otro, tender bajo la común oposición al marxismo un puente de entendimiento con las democracias parlamentarias.

Pero de momento, como dijimos, El Día se entregó a festejar por todo lo alto la formidable embestida de la todavía invicta Wehrmacht contra la Unión Soviética, lo que el 6 de julio de 1941, en vísperas de la partida del primer contingente de la División Azul para el frente, le hizo exclamar: "ayer, contra el comunismo en España; ahora, contra el mismo enemigo en Rusia." Tres meses más tarde, ante lo que parecía un paseo militar hacia Moscú en un momento en el que toda Europa, con la única excepción de Gran Bretaña, estaba bajo el control alemán, el órgano tinerfeño del Movimiento estaba tan eufórico que, el 12 de octubre, con motivo del Día de la Raza, recuperó por momentos su discurso bélico: “como José Antonio gritó un día: ¡Castilla, otra vez por España! Gritamos también nosotros hoy, desde este mar de descubrimiento: ¡España, otra vez por América! [...] para salvarla de la avalancha antiespañola de prestamistas [referencia a los Estados Unidos] y rehacer, frente al imperialismo, el Imperio de la Hispanidad." ${ }^{17}$ Pero antes de dos meses, cuando la llegada del invierno se encargó de echar por tierra los planes alemanes en Rusia, el periódico reconsideraba de nuevo su postura para, el 29 de noviembre, advertir tanto a "los que esperen el triunfo de Rusia para revolverse de nuevo contra nosotros... [como a]... los que anhelan la derrota de Rusia para una vuelta a la economía liberal, del polipartidismo y de todas sus miserias... [que]... España seguirá su irrenunciable destino."

\section{La otra palanca para acercarse a los países aliados: el catolicismo}

El ataque por sorpresa de la aviación japonesa a la base de Pearl Harbour, que hizo recordar las operaciones de la Wehrmacht en Europa, fue justificado por $E l$ Día el 9 de diciembre de 1941, con la tradicional demora que abordaba las novedades

\footnotetext{
${ }^{17}$ Estos términos "cautelosos, no agresivos, casi metafísicos", fueron una constante en todas las peroratas imperialistas de los ideólogos del franquismo durante la II Guerra Mundial (Stanley G. Payne) 281-282.
} 
más delicadas, aduciendo que "Japón quería romper el cerco económico impuesto por el oro yanqui, manejado por el capitalismo judío [...] Ha comenzado la guerra con la demostración, por parte de Japón, de una poderosa organización bélica [...] Para nosotros, la contienda tiene su lado bello, heroico y digno." Dos meses más tarde, el 17 de febrero de 1942, cuando la expansión nipona por el Pacífico proseguía sin encontrar resistencia porque los Estados Unidos todavía no se habían recuperado del golpe asestado por la aviación nipona, el periódico veía con cierto optimismo la situación de las tropas alemanas en el frente oriental porque, aunque "Alemania es la primera que ha reconocido que Rusia es el único enemigo serio del continente," este país "no ha hecho más que perder kilómetros y kilómetros y dejar en manos del contrario sus industrias guerreras." Semanas más tarde, cuando la primavera ya empezaba a dejarse notar, el diario tinerfeño pronosticaba el 8 de abril, bajo el elocuente titular "Adiós general invierno," el cese de la contraofensiva soviética y la victoria inminente de la Wehrmacht.

Pero luego, en pleno período estival de 1942, cuando los hechos dejaron patente que la lucha en el frente oriental iba para largo, El Día volvió a recoger velas y a centrar su discurso, por encima de otras consideraciones, en sus fobias contra Rusia. Así, el 2 de agosto, el otrora diario germanófilo había escorado tanto su línea editorial que ya decía cosas como ésta: "una vez y cien veces, hasta que en saciedad se rindan los voluntariamente negados a la comprensión: el comunismo es nuestro enemigo [...] El mundo se debate hoy en un trágico conflicto en el que las legiones del Mal [referencia a la Unión Soviética] toman partido. No nos interesan los nombres de las naciones que luchan ni qué ocultos designios se procuran con las armas... [Solo,]... la participación del comunismo en la lucha. Este mero hecho es suficiente para definir la postura de un pueblo". En consecuencia, aunque tales aseveraciones quedaban en evidencia ante el reciente alineamiento con la Alemania nazi, sin hacerle ascos al pacto de no agresión firmado por ésta con la Unión Soviética, el periódico ahora no sentía rubor alguno para, el 29 de septiembre, cuando la batalla de Stalingrado se había estancado y las nevadas eran de nuevo inminentes, decir que el hecho de ser "absolutamente incompatible con el comunismo" había sido el único factor que había determinado su posicionamiento en la contienda.

Una vez reducida la referencia negativa del discurso a la Unión Soviética, el siguiente paso del giro doctrinario consistió en buscar un sustituto al fascismo para la argumentación en positivo. El recambio fue el catolicismo, un componente ideológico presente desde el inicio de la Guerra Civil que se hizo cada vez más visible a partir de mediados de noviembre de 1942, en coincidencia con el agravamiento de la situación de las tropas alemanas en el frente oriental, el inicio de la contraofensiva británica en El Alamein y el desembarco angloamericano en Marruecos y Argelia. A partir de entonces, al margen de hablar con reiteración, como hiciera el 8 de diciembre de 1942, del "sentido católico de nuestra política," El Día elevó el susodicho ingrediente religioso a un lugar tan alto de su ideario que el 24 de febrero de 1943, tres semanas después de la rendición alemana en Stalingrado, ${ }^{18}$ esbozó una concepción del viejo

\footnotetext{
${ }^{18}$ El inicial posicionamiento nazi y el viraje ideológico del régimen tras la derrota de Stalingrado han
} 
continente muy alejada del "nuevo orden fascista" que había defendido a inicios de la guerra: "para nosotros, Europa significa, precisamente, el centro de la catolicidad en toda la extensión de ese concepto, en el sentido religioso, político, poético y universal." En meses sucesivos, al tiempo que nos legaba un testimonio de la progresiva derrota alemana sin poder ocultar su trasfondo ideológico nazi, el desconocido diario acentuó su canto a los valores del catolicismo ${ }^{19}$ y sus arremetidas contra el comunismo para, al amparo de ambos referentes, empezar a hablar de los problemas de la posguerra, como hiciera el 11 de agosto de 1943, cuando advirtió a las democracias parlamentarias que "Rusia quiere una Alemania bolchevique militarmente potente."

\section{La apostasía del fascismo}

El último paso del viraje argumentativo del órgano oficial del Movimiento en Tenerife empezó a fraguarse el 1 de octubre de 1943, cuando Franco, tres semanas después de la capitulación de Italia, calificó de neutralidad vigilante ${ }^{20}$ la postura de España ante la guerra en un discurso que pronunció delante del cuerpo diplomático acreditado en Madrid "con uniforme de almirante en vez de con el traje falangista." 21 Una semana más tarde, el 7 de octubre, cuando los exiliados españoles recrudecían su campaña en pro de la intervención aliada para erradicar el fascismo de España, el periódico insistía en que la sublevación militar de julio de 1936 había sido llevada a cabo, exclusivamente, contra el marxismo: "hemos de salir al paso de cuantas intrigas intenten establecer paralelismos [...] con el fin de echar sombras sobre nuestra posición". Luego, tras insistir el 13 de noviembre que "el muro de contención a todo posible intento comunista está levantado en nuestra Patria por Falange”, el periódico ponía la guinda a su espectacular mutación ideológica en un amplio editorial publicado el 26 de enero de 1944 en el que, bajo el desconcertante titular "Ni comunismo ni fascismo" se hacía eco de un comentario del diario madrileño El Español para afirmar que "Falange Española Tradicionalista y de las JONS NO ES UN MOVIMIENTO FASCISTA [con mayúsculas, como si levantara la voz]; tiene con el fascismo algunas coincidencias en puntos esenciales de valor universal, pero va perfilándose cada día con caracteres peculiares y está segura de encontrar, precisamente, por ese camino, sus posibilidades más fecundas".

Los temores a la censura en estos tres meses escasos en los que España pasó de la no beligerancia pronazi a la neutralidad vigilante para, a renglón seguido, desmarcarse del fascismo, quedaron en evidencia en las propias páginas del periódico. En efecto, para garantizar que los espacios de opinión se atenían con escrupulosidad

sido estudiados en la prensa editada en Madrid y, sobre todo, en Barcelona, la que con demora y muchas cautelas secundaba El Día, en la obra de Francesc Vilanova i Vila-Abadal, El franquismo en guerra. De la destrucción de Checoslovaquia a la batalla de Stalingrado (Barcelona, Editorial Península, 2005).

${ }^{19} \mathrm{Al}$ parecer, el catolicismo también fue utilizado en el tramo final de la guerra para marcar distancias con la Alemania nazi sobre la base de que el régimen de Franco "no tenía nada que ver con el fascismo porque no podía España ligarse ideológicamente con quienes no tuvieran la catolicidad como principio", argumentación que, sin embargo, nunca vimos esgrimida en El Día (Stanley G. Payne, 349).

${ }^{20}$ Morales Lezcano, 53-62.

${ }^{21}$ Stanley G. Payne, 344. 
a las mutantes consignas que, en paralelo al mencionado viraje, llegaban de la península, el rotativo tinerfeño se entregó a comentar en mayor medida que en tiempos pasados los editoriales y artículos de los ideólogos del régimen que el día anterior habían publicado Arriba, El Alcázar, El Español o $A B C$ en Madrid. Por si fueran pocas las cautelas, debajo del paraguas que brindaba la argumentación que ya había pasado la censura, los textos de cosecha propia se limitaban a reiterar las ideas menos comprometedoras, como el 20 de febrero de 1944, cuando se hablaba del "derecho indiscutible a vivir nuestra vida y nuestra paz"; el 21 de mayo, cuando se insistía en que "nuestro Estado ni es una copia ni un influjo del exterior, porque en él no prevalece nada más que nuestra propia tradición"; el 29 de junio, ya con el desembarco en Normandía abriendo brecha en las defensas alemanas, cuando advertía a los países aliados: "no nos despistemos más. Moscú manda: Moscú triunfa en toda Europa"; o el 13 de agosto, cuando abordó el tema que a partir de entonces se haría más recurrente: "nuestro Movimiento es la paz, el orden, la seguridad y la legalidad".

Al margen de justificar la neutralidad desde todos los puntos de vista posibles, de arremeter cada vez con mayor saña contra la Unión Soviética, de desmentir por activa y por pasiva el alineamiento con las potencias fascistas y de elevar el componente católico a la cúspide de su ideario, El Día se ocupó a partir de entonces de presentar a España como un remanso de paz en un mundo hostil que la guerra había convertido en un infierno. De aquí a la fabricación del célebre mito de la "reserva espiritual de Occidente" solo había un pequeño trecho que, en estos meses finales de la contienda, el periódico empezó a recorrer, tal y como ilustra el editorial del 9 de marzo de 1945 que, bajo titular "La Península Ibérica constituye un tesoro moral del mundo", se hizo eco de unas recientes declaraciones del director de Arriba, Xavier Echarri, al Diario Popular de Lisboa.

\section{La reclinación servil ante los aliados}

Mientras tanto, con el trasfondo del incontenible avance aliado en todos los frentes, El Día había reproducido unas palabras pronunciadas por Franco para, el 3 de agosto de 1944, afirmar que "España se encuentra dispuesta a la colaboración con todos los países". Con tal actitud, ya traducida en el apoyo logístico dado a las tropas angloamericanas, el periódico reclamaba el respeto al sistema político de cada país, con lo que una vez más se contradecía por sus continuas peroratas contra la Unión Soviética, aduciendo que "el orden interior y la economía son cosa de cada nación; que, si hay otro orden y otra economía superiores en lo internacional, no pueden ser más que la suma o el concierto de los nacionales." Paralelamente, el otro diario germanófilo se dedicaba a recopilar los servicios prestados por el régimen franquista a los países que a inicios de la guerra había llamado continuamente, como hiciera el 12 de junio de 1940, "democracias cargadas de charlatanería, obtusas y culpables de tantas tragedias". En tal empeño, el periódico resucitó el célebre discurso que Churchill pronunciara seis meses atrás en el parlamento británico para, el 9 de noviembre de 1944, decir que "nada menos que el primer ministro inglés [...] ha reconocido de forma universal que la actitud neutral de España, precisamente, en el instante en que Inglaterra no contaba con un aliado eficaz en Europa, hizo cambiar 
la suerte de la guerra". En definitiva, la versión de los hechos había dado un vuelco tan espectacular en las páginas de El Día que, según éstas, los aliados iban a ganar la guerra gracias a Franco.

En estos meses finales de la contienda, el periódico nunca ocultó las presiones cada vez más insistentes de los españoles expatriados en favor de la intervención aliada contra el régimen franquista, como tampoco el escaso temor que éstas le producían. Las razones de todo ello quedaron resumidas, por ejemplo, el 20 de febrero de 1945, cuando reprodujo un artículo del periodista mejicano Alfonso Junco ${ }^{22}$ en el que, tras comentar la alarma que estaba suscitando entre las potencias anglosajonas el avance de la Unión Soviética en la Europa oriental, se preguntaba: “¿qué móvil podría acuciarlos a crear en la Península un problema que no tienen, y a suplantar un gobierno responsable con el que están en relación sin conflicto y que es garantía eficaz contra infiltraciones comunistas, para montar un régimen que mañana resultara arrollado por la penetración soviética?". Tales argumentos fueron retomados con posterioridad en un sinfín de editoriales propios y en artículos de autoría ajena procedentes, incluso, de la prensa anglosajona, caso del que bajo el titular "El imperialismo soviético" publicó el periodista norteamericano Karl von Wiegant en los periódicos del grupo Hearst, que reprodujo el 4 de mayo de 1945, a los dos días de anunciar el suicidio de Hitler: "Una de las mayores paradojas [...] de esta guerra es que al intentar establecer una verdadera democracia y sus libertades en Europa, hemos allanado el camino para el comunismo soviético y toda su tiranía, y al acabar con el nazismo y el fascismo y sus arbitrarios sistemas de dictadura, hemos logrado elevar a potencia mundial a otro sistema dictatorial mucho mayor, más fuerte y absolutista". En definitiva, El Día ya se hacía eco del afloramiento de la guerra fría y, con ella, del paraguas que habría de garantizar la continuidad del régimen franquista con su simple puesta al servicio de los intereses de los Estados Unidos.

\section{El encontronazo con la realidad en la posguerra}

Por sorprendente que pueda resultar, el periódico empezó a hablar del papel que la posguerra le reservaba a España, dando por sentada la victoria aliada, sobre la base de que, como hiciera el 14 de septiembre de 1944, "nuestra posición de neutralidad nos confiere derechos indiscutibles y nos capacita para una importante intervención en los debates que han de promoverse en torno a la reconstrucción material y moral que el mundo reclama en las horas de paz". Al hilo de tal argumentación, el 14 de febrero de 1945, se apoyaba en el contenido de una carta que, según decía, había publicado un ciudadano británico residente en España en The Times para insistir que Franco "hizo saber a Hitler y a Mussolini que se opondría a toda invasión, viniera de donde viniera", lo que había beneficiado a la causa aliada porque, añadía, "si hubiera seguido otro camino cualquiera, los alemanes se hubieran vuelto contra de él y hubiera cedido España y cerrado el Mediterráneo", con lo que las tropas norteamericanas no hubieran podido atacar el "punto flaco de Europa." Fue por entonces, a semanas vista

\footnotetext{
${ }^{22}$ Periodista mexicano que, por entonces, sostuvo encendidas polémicas con los españoles exiliados en aquella república (Ana Boned Cólera, "La propaganda antifascista del exilio español", Historia y Comunicación Social, 6 (2001): 293-302.
} 
de la rendición de Alemania, cuando el régimen franquista aprovechó el "exterminio de nuestros infortunados compatriotas" en Manila para romper sus relaciones diplomáticas con Japón, lo que el diario tinerfeño interpretó el 12 de abril de 1945, tras correr un tupido velo sobre tan errática trayectoria, como un episodio más de la "defensa del honor y la dignidad de España"23 por Franco.

El terreno de la inminente posguerra también fue abonado con otras tesis no menos antagónicas a las que había rumiado dos años atrás con la esperanza de tender, a través de los lazos históricos de España con Latinoamérica, otro puente de entendimiento con las potencias anglosajonas. En efecto, por entonces, las peroratas contra la influencia yanqui en las antiguas colonias hispanas habían dado paso a una argumentación fraternal en la que se reivindicaba, como el 5 de abril de 1945, una "fuerte solidaridad moral y material con América toda [...] no ya con la propiamente hispánica... [sino también con]... la anglosajona y la lusitana”. El propósito del cambio del discurso salió a relucir una semana más tarde, el 12 de abril, cuando el errático diario abogaba por la "necesidad de una compenetración, de una amistad y de una colaboración, entre todos esos países que viven y laboran en ambos lados del Atlántico". Por entonces, a las continuas disquisiciones sobre "las corrientes de inteligencia y amistad que nos unen con la gran nación norteamericana”, se unía una versión tan diferente a la inicial de la figura del presidente Roosevelt que el 13 de abril de 1945, tras su repentino fallecimiento, el periódico llegó a elogiar hasta su "decidida intervención en la guerra", lo que, implícitamente, conllevaba la reprobación de la política de su, por lo demás, siempre admirado Adolf Hitler.

Como es de sobra conocido, tales esfuerzos dialécticos resultaron vanos, lo que quedó magníficamente testimoniado en las propias páginas de El Día que, tras acoger el 9 de mayo de 1945 la rendición de la Alemania nazi bajo el titular "España comparte la alegría de la paz," pronto empezaron a recrear las secuelas del aislamiento al que estaba condenado el régimen franquista. Antes de los tres meses, cuando los peores augurios se hicieron realidad en la declaración de Postdam con la condena del régimen franquista por la $\mathrm{ONU}$, el periódico recobró por momentos su viejo discurso arrogante para, el 5 de agosto de 1945, afirmar que "España no mendiga un puesto en las conferencias internacionales ni aceptará el que no estuviese en relación con su Historia, su población y sus servicios a la paz y la cultura." Tales bravuconadas, por lo demás, también eran meras falacias porque, como es sabido por todos, Franco se puso dócilmente al servicio de los Estados Unidos durante la guerra fría.

\section{Conclusiones}

En los años de la II Guerra Mundial, el sistema informativo de las Islas Canarias perdió la singularidad con la que había funcionado hasta entonces para, a remolque de la centralización del aparato propagandístico del régimen franquista en

\footnotetext{
${ }^{23}$ Precedente de tal posicionamiento fue la teoría de las tres guerras que, con la desigual postura de España ante cada una de ellas, expusiera públicamente Franco desde el inicio de la contraofensiva norteamericana en el Pacífico: neutral en el enfrentamiento de los aliados y la Alemania nazi, a favor de Alemania en su ataque a la Unión Soviética y contra Japón en el Pacífico (Stanley G. Payne, 328).
} 
Madrid, quedar inmerso, como nunca lo había estado en su historia, en el sistema informativo estatal. Bajo tales premisas, el estudio evolutivo del órgano oficial del Movimiento en la provincia de Santa Cruz de Tenerife, El Día, nos ha recreado magníficamente los erráticos cauces por los que la prensa española movió su línea editorial en aquellos años bélicos, al ritmo que marcaban las consignas, la labor realizada desde dentro de los propios periódicos por los directores nombrados al efecto y la intimidación de la brutal censura, con el exclusivo propósito de conseguir, en un principio, el mayor botín posible de la deseada victoria de la Alemania nazi y, luego, desde que tales posibilidades se esfumaron por la intervención de los Estados Unidos, la simple supervivencia del franquismo en la posguerra.

Dentro de la uniformidad compartida con toda la prensa española, el rasgo más distintivo del periódico analizado por nosotros ha sido, sin duda, por el alejamiento de Madrid, el temor a salirse del guion que fue marcando la cambiante actitud del régimen franquista ante el desarrollo de la contienda. Tal circunstancia se hizo visible en la demora, en unos dos o tres días, con que se abordaban los asuntos novedosos del día a día, el uso abusivo de los textos publicados previamente por la prensa madrileña que, por lo tanto, ya tenían la bendición de la censura, o el comedimiento con que se trataban los temas más delicados. Por lo tanto, la desconexión del centro donde se tomaban las decisiones, al mitigar los excesos de las contradicciones esgrimidas entre las sucesivas coyunturas, hacen que las páginas de El Día sean uno de los documentos que con mayor claridad testimonian el giro que, desde el alineamiento con la Alemania nazi hasta la sumisión a los Estados Unidos, experimentó la política del general Franco en aquellos trágicos años.

\section{Bibliografía}

\section{Fuentes primarias}

\section{Fuentes hemerográficas}

El Día (1939-1945) de S/C de Tenerife, del que se citan los números siguientes: Año I, núm. 50, 15 de abril de 1939, 1. Año I, núm. 51, 16 de abril de 1939, 1. Año I, núm. 54, 20 de abril de 1939, 1. Año I, núm. 57, 23 de abril de 1939, 1. Año I, núm. 62, 29 de abril de 1939, 1. Año I, núm. 122, 2 de julio de 1939, 4, único texto ubicado en página interior. Año I, núm. 166, 23 de agosto de 1939, 1.

Año I, núm. 260, 10 de diciembre de 1939, 1.

Año I, núm. 296, 20 de enero de 1940, 1.

Año II, núm. 343, 15 de marzo de 1940, 1.

Año II, núm. 362, 7 de abril de 1940, 1.

Año II, núm. 396, 18 de mayo de 1940, 1.

Año II, núm. 398, 21 de mayo de 1940, 1. 
Año II, núm. 408, 1 de junio de 1940, 1. Año II, núm. 413, 6 de junio de 1940, 1. Año II, núm. 416, 12 de junio de 1940, 1. Año II, núm. 423, 20 de junio de 1940, 1. Año II, núm. 450, 21 de julio de 1940, 1. Año II, núm. 428, 27 de julio de 1940, 1. Año II, núm. 510, 27 de septiembre de 1940, 1. Año II, núm. 515, 1 de octubre de 1940, 1. Año III, núm. 730,15 de abril de 1941, 1. Año III, núm. 731,16 de abril de 1941, 1. Año III, núm. 740, 3 de junio de 1941, 1. Año III, núm. 765, 25 de junio de 1941, 1. Año III, núm. 775, 6 de julio de 1941, 1. Año III, núm. 861,12 de octubre de 1941, 1. Año III, núm. 901, 29 de noviembre de 1941, 1. Año III, núm. 909, Año III, núm. ,9 de diciembre de 1941, 1. Año III, núm. 968,17 de febrero de 1942, 1. Año IV, núm. 1010, 8 de abril de 1942, 1. Año IV, núm. 1116, 2 de agosto de 1942, 1. Año IV, núm. 1167, 29 de septiembre de 1942, 1. Año IV, núm. 1228, 8 de diciembre de 1942, 1. Año IV, núm. 1294, 24 de febrero de 1943, 1. Año V, núm. 1409, 11 de agosto de 1943, 1. Año V, núm. 1481, 1 de octubre de 1943, 1. Año V, núm. 1486, 7 de octubre de 1943, 1. Año V, núm. 1519, 13 de noviembre de 1943, 1. Año V, núm. 1580, 26 de enero de 1944, 1. Año V, núm. 1, 1602, 20 de febrero de 1944, 1. Año VI, núm. 1680, 21 de mayo de 1944, 1. Año VI, núm. 1714, 29 de junio de 1944, 1. Año VI, núm. 1746, 3 de agosto de 1944, 1. Año VI, núm. 1754, 13 de agosto de 1944, 1. Año VI, núm. 1782, 14 de septiembre de 1944, 1. Año VI, núm. 1830, 9 de noviembre de 1944, 1. Año VI, núm. 1910, 14 de febrero de 1945, 1. Año VI, núm. 1915, 20 de febrero de 1945, 1. Año VII, núm. 1931, 9 de marzo de 1945, 1. Año VII, núm. 1954, 5 de abril de 1945, 1. Año VII, núm. 1960, 12 de abril de 1945, 1. Año VII, núm. 1961, 13 de abril de 1945, 1. Año VII, núm. 1979, 4 de mayo de 1945, 1. Año VII, núm. 1983, 9 de mayo de 1945, 1. Año VII, núm. 2058, 5 de agosto de 1945, 1. 


\section{Fuentes secundarias}

\section{Libros}

Díaz Benítez, Juan José. Canarias indefensa: los proyectos de ocupación de las islas durante la II Guerra Mundial. Santa Cruz de Tenerife: Ediciones Idea, 2008.

Díaz Benítez, Juan José. Anglofilia y autarquía en Canarias durante la Segunda Guerra Mundial. Santa Cruz de Tenerife: Ediciones Idea, 2008.

Estupiñán Bethencourt, Francisco. La escritura entre líneas. El artículo de opinión en El Día entre 1966 y 1975. Santa Cruz de Tenerife: Universidad de La Laguna, 1998.

Fernández Areal, Manuel. El control de la Prensa en España. Madrid: Editorial Guadiana, 1973.

Lemus, Encarnación y Manuel Peña (coord.). Alianzas y propaganda durante el primer franquismo. Barcelona: Ariel, 2019.

Morales Lezcano, Víctor. Canarias en la II Guerra Mundial. Las Palmas de Gran Canaria: Edirca, 1995.

Payne, Stanley G. El régimen de Franco, 1936-1975. Madrid: Alianza Editorial, 1987.

Payne, Stanley G. Franco y Hitler. España, Alemania, la Segunda Guerra Mundial y el Holocausto. Madrid: La Esfera, 2008.

Tusell, Javier. Franco, España y la II Guerra Mundial. Entre el Eje y la neutralidad. Madrid: Temas de Hoy, 1995.

Sinova, Justino: La censura de Prensa durante el franquismo (1936-1951). Madrid: Espasa-Calpe, 1989.

Vilanova i Vila-Abadal, Francesc. El franquismo en guerra. De la destrucción de Checoslovaquia a la batalla de Stalingrado. La falsa neutralidad española durante la Segunda Guerra Mundial al descubierto. Un mito que ha llegado hasta hoy, Barcelona, Editorial Península: 2005.

Yanes Mesa, Julio Antonio. Leoncio Rodríguez y «La Prensa»: una página del periodismo canario. Santa Cruz de Tenerife: Cabildo Insular de Tenerife, 1995.

Yanes Mesa, Julio Antonio. Historia del Periodismo Tinerfeño, 1758-1936. Una visión periférica de la Historia del Periodismo Español. Santa Cruz de Tenerife: Centro de la Cultura Popular Canaria, 2003. 


\section{Artículos de revistas}

Boned Cólera, Ana. «La propaganda antifascista del exilio español». Historia y Comunicación Social, 6 (2001): 293-302.

García Cabrera, Marta. "De la neutralidad oficial a la no beligerancia española en la II Guerra Mundial: análisis a través de la prensa canaria”, Anuario de Estudios Atlánticos, 64 (2018): 1-18. URL: anuariosatlanticos.casadecolon.com/index.php/ aea/article/view/10162/9644.

Tena Fernández, Ramón, Ana Margarida Ramos y José Soto Vázquez. “Análisis comparativo de la censura de la LIJ en España y Portugal a través de la legislación promulgada durante las dictaduras de Franco y Salazar". Bulletin of Spanish Studies, 96, 10 (2019): 1657-1679.

Yanes Mesa, Julio Antonio. "The Final Setting of the Golden Age of the Press in the World: The Canary Islands During the Spanish Second Republic (1931-1936)". Ámbitos. Revista internacional de comunicación, 19 (2010): 284-296.

Yanes Mesa, Julio Antonio. "La propaganda radiofònica de 1'Espanya nacional a Canàries Durant la Guerra Civil, 1936-1939”. Anàlisi. Quaderns de comunicació y cultura, 41 (2011): 101-116. 